\title{
Immobilization of Lipase Inhibitor on the Biopolymers from Agaricus bisporus Cell Walls
}

\author{
Natalya Cherno, Sophya Osolina and Oleksandra Nikitina* \\ Research Laboratory, Odessa National Academy of Food Technologies, Kanatnya str 112, \\ UA-65039 Odessa, Ukraine \\ Received: July 24, 2016 \\ Accepted: November 2, 2017
}

\begin{abstract}
Summary
One of the methods for curing obesity is the inclusion of some substances with the antilipase activity in the diet and thus reducing the uptake of fat components from food. The aim of this research is to provide a stabilized form of lipase inhibitor by immobilization of enzyme on the biopolymers from Agaricus bisporus cell walls. The phenolic compounds extracted from the rapeseed were considered as the lipase inhibitor. The activity of the inhibitor was considerably reduced in the gastric juice, as well as at temperatures above $37^{\circ} \mathrm{C}$ and during its storage, which determined the suitability of the inhibitor for stabilization on the matrix. The effectiveness of the phenolic compound stabilization was investigated by means of immobilization on the biopolymers from Agaricus bisporus cell wall matrix. The biopolymers used were $\beta$-glucan, chitin, melanin and proteins. A number of samples, which differed both in the content of the inhibitor (from 1 to $16 \%$ ) and in the ratio of biopolymers in the matrix composition, was obtained. The conditions of immobilization (temperature, duration of the process) were also varied. The expediency of obtaining the sample with the inhibitor content of $12 \%$ and matrix containing $47.9 \%$ of glucan, $18.8 \%$ of chitin, $18.8 \%$ of melanin and $11.1 \%$ of proteins was shown. The best immobilization was carried out at $20-25{ }^{\circ} \mathrm{C}$ for $30 \mathrm{~min}$. Thermal analysis and infrared spectroscopy data confirmed that immobilization of the lipase inhibitor on the matrix was due to the hydrogen bonds. The immobilized inhibitor had higher $\mathrm{pH}$ stability and higher thermal stability than the original one. The remaining activity of the immobilized inhibitor was higher than the original one after incubation in the gastric acid and bile. The immobilized inhibitor was characterized by a low loss of activity after 12 months of storage.
\end{abstract}

Key words: lipase inhibitor, biopolymers, immobilization, mushroom, rapeseed

\section{Introduction}

In recent decades, the population of many countries has faced the problem of obesity $(1,2)$. For a long time we believed that it did not have a serious impact on the human health. However, at the turn of the 21st century, the World Health Organization has changed its opinion on this problem. The results of medical studies have shown that the chronic form of obesity is a disease associated with insulin-independent diabetes, hypertension, atherosclerosis, gallstone disease and some malignant diseases. In addition, the medical prognosis is unfavourable, as the number of patients that suffer from chronic obesity is in- creasing; every second inhabitant of our planet will face this problem in 10 years (2-4).

In order to fight against this disease, scientists have developed the number of drugs. However, a detailed study of their impact on the human body revealed that only one of them is safe to use. It is a drug called Xenical (orlistat). This product is obtained by hydrogenation of lipstatin (5-7).

Orlistat inhibits the lipase activity in the human body. It reduces decomposition of exogenous fats and facilitates their excretion from the body. Thus, it shows antilipase activity and reduces the digestibility of fat. However, in some cases, its application is accompanied by a violation of the

"Corresponding author: Phone: +380 95192 4212; E-mail: alex.nikitina@gmail.com 
qualitative and quantitative composition of the intestinal microflora. This, in turn, can disrupt the balance of the entire microbial-intestinal tissue complex (8).

Inhibitors of pancreatic lipase derived from the plant sources have no side effects. They do not cause addiction or allergies and they are nontoxic, in contrast to microbial inhibitors (9). Therefore, the development of antilipase drugs produced from plant sources is relevant.

Some existing dietary supplements that contain plant components can inhibit the lipase action. They are manufactured in Indonesia and include products from leaves or extracts of Guazuma ulmifolia and Brassicaceae family plants. They show antilipase activity due to the phenolic compounds. When coffee beans and leaves of black and green tea are included in the dietary supplements, the alkaloids and the catechins of the raw materials are the active compounds inhibiting lipase (10-13). However, application of some dietary supplements that contain the sources of lipase inhibitors listed above has several disadvantages. They have some antinutrients, such as the cyanogenic glycosides and alkaloids $(14,15)$.

Among the European plants, the plant families Leguminosae, Cruciferae, Papaveraceae, Apiaceae and Brassicaceae have the highest antilipase activity (10). However, due to the climate conditions, plants that grow in Europe have lower antilipase activity than Indonesian ones. The rapeseed, which belongs to the family Brassicaceae, is the prospective source of the compounds with antilipase activity. The advantage of this culture as a raw material for producing lipase inhibitors is that the rapeseed is one of the most productive oilseed crops in the world. Therefore, in recent years, its cultivation area had increased. Furthermore, not only rapeseed but also some by-products of its processing can be used as a source of phenolic compounds.

The phenolic acids, as well as the soluble and insoluble tannins are the main carriers of the antilipase activity in the rapeseed $(16,17)$. The phenolic acids derived from benzoic and cinnamic acids occur in the rapeseed in the free and bound forms. The sinapic acid and its derivative sinapine (choline ester of 3,5-dimethoxy-4-hidroxycinnamic acid) predominate among the phenolic acids in the rapeseed (18).

Direct addition of rapeseed into dietary supplements as a source of the lipase inhibitor is not recommended, due to its low content of phenolic compounds and antinutrient substances, particularly erucic acid and glycosinolates (10). The rapeseed phenolic compounds extracted from the raw materials are unstable and they rapidly lose their antilipase activity. Therefore, it is important to obtain the type of the inhibitor that will be resistant to external influences.

Immobilization is one of the well-known methods of stabilizing biologically active substances $(19,20)$. Considering that the purpose of immobilization is to obtain the phenolic compounds that are resistant to the environmental influence, we regarded biopolymers from Agaricus bisporus cell walls as a matrix (21), chosen for their antioxidant and antacid properties. The first goal was to create the prerequisites for preserving the antilipase activity of the inhibitor during storage and the second to protect it against the influence of the acid medium during passage through the stomach.
The aim of this research is to obtain the stabilized form of the lipase inhibitor by its immobilization on the biopolymers from Agaricus bisporus cell walls.

\section{Materials and Methods}

\section{Materials}

All reagents and standards were obtained from Sigma-Aldrich Corp. (St. Louis, MO, USA). Agaricus bisporus was purchased at the farm that cultivates mushrooms, Geleka-M Company (Odessa, Ukraine). The fruiting bodies were cleaned, dried and milled. The rapeseed (Brassica napus) was obtained from List Company (Kiev, Ukraine). The drug Xenical was from Roche (Basel, Switzerland).

\section{Preparation of matrices for inhibitor immobilization}

During the experimental research, samples of Agaricus bisporus biopolymers were used as a matrix for the inhibitor immobilization. Solid residues were obtained after the sequential treatment of the mushroom with three extraction agents: boiling water for $90 \mathrm{~min}, 3.7 \% \mathrm{HCl}$ at $25^{\circ} \mathrm{C}$ for 150 min and 3 or $7 \% \mathrm{NaOH}$ at $98{ }^{\circ} \mathrm{C}$. The duration of the alkaline treatment was 60 or $300 \mathrm{~min}$ (Table 1). The solid residue was washed until the neutral $\mathrm{pH}$ was obtained and then it was freeze dried. The matrix without melanin was obtained by the additional treatment of sample 5 (Table 1) with $8 \%$ $\mathrm{H}_{2} \mathrm{O}_{2}$ solution for $60 \mathrm{~min}$ at room temperature.

Table 1. Conditions used for obtaining samples of matrices

\begin{tabular}{|c|c|c|c|c|c|}
\hline Sample & & Water & $\begin{array}{c}w(\mathrm{HCl}) \\
=3.7 \%\end{array}$ & $w(\mathrm{NaOH}) / \%$ & $w\left(\mathrm{H}_{2} \mathrm{O}_{2}\right) / \%$ \\
\hline 1 & $\begin{array}{c}t /{ }^{\circ} \mathrm{C} \\
\text { Time/ } \\
\text { min }\end{array}$ & $\begin{array}{c}100 \\
90\end{array}$ & $\begin{array}{c}25 \\
150\end{array}$ & $\begin{array}{c}3 \\
98 \\
60\end{array}$ & - \\
\hline 2 & $\begin{array}{c}t /{ }^{\circ} \mathrm{C} \\
\text { Time/ } \\
\min \end{array}$ & $\begin{array}{c}100 \\
90\end{array}$ & $\begin{array}{c}25 \\
150\end{array}$ & $\begin{array}{c}3 \\
98 \\
300\end{array}$ & - \\
\hline 3 & $\begin{array}{c}t /{ }^{\circ} \mathrm{C} \\
\text { Time/ } \\
\text { min }\end{array}$ & $\begin{array}{c}100 \\
90\end{array}$ & $\begin{array}{c}25 \\
150\end{array}$ & $\begin{array}{c}7 \\
98 \\
60\end{array}$ & - \\
\hline 4 & $\begin{array}{c}t /{ }^{\circ} \mathrm{C} \\
\text { Time/ } \\
\text { min }\end{array}$ & $\begin{array}{c}100 \\
90\end{array}$ & $\begin{array}{l}25 \\
150\end{array}$ & $\begin{array}{c}7 \\
98 \\
300\end{array}$ & - \\
\hline 5 & $\begin{array}{l}t /{ }^{\circ} \mathrm{C} \\
\text { Time/ } \\
\text { min }\end{array}$ & $\begin{array}{c}100 \\
90\end{array}$ & $\begin{array}{c}25 \\
150\end{array}$ & $\begin{array}{c}7 \\
98 \\
60\end{array}$ & $\begin{array}{l}8 \\
60\end{array}$ \\
\hline
\end{tabular}

\section{Determination of chemical composition of matrices}

Matrices were treated with $72 \% \mathrm{H}_{2} \mathrm{SO}_{4}$ at room temperature for $150 \mathrm{~min}$. Water was added to decrease acid volume fraction to $5 \%$. Then the matrices were hydrolysed for another $300 \mathrm{~min}$ at the boiling temperature (22). Melanin content was determined by UV-Vis spectrophotometer (UV-2401 PC; Shimadzu Corp., Kyoto, Japan) at the wavelength $\lambda=490 \mathrm{~nm}$ (23). The polysaccharide content (except chitin) was determined by the anthrone method. A volume of $4 \mathrm{~mL}$ of anthrone reagent $(1 \mathrm{mg}$ of anthrone 
per $1 \mathrm{~mL}$ of $\mathrm{H}_{2} \mathrm{SO}_{4}$ ) was added to $0.5 \mathrm{~mL}$ of working solution, the mixture was bathed for $15 \mathrm{~min}$, cooled to the room temperature, and the absorbance was measured by UV-Vis spectrophotometer (UV-2401 PC; Shimadzu) at $\lambda=670 \mathrm{~nm}$ (24). The glucosamine content was evaluated with 3-methyl-2-benzothiazolone hydrazone hydrochloride according to Lane Smith and Gilkerson (25). To $1 \mathrm{~mL}$ of the sample solution, $1 \mathrm{~mL}$ of $5 \% \mathrm{KHSO}_{4}$ and $1 \mathrm{~mL}$ of $5 \%$ $\mathrm{NaNO}_{2}$ were added. The mixture was shaken at $5000 \mathrm{rpm}$ for $15 \mathrm{~min}$, then $1 \mathrm{~mL}$ of $12.5 \% \mathrm{NH}_{4} \mathrm{SO}_{3} \mathrm{NH}_{2}$ was added and shaken for $5 \mathrm{~min}$. A volume of $1 \mathrm{~mL}$ of $0.5 \% 3$-methyl-2-benzothiazolone-hydrazone-hydrochloride was added and the mixture was left to settle for $60 \mathrm{~min}$. Then $1 \mathrm{~mL}$ of $0.5 \% \mathrm{FeCl}_{3}$ was added and the absorbance was measured by UV-Vis spectrophotometer (UV-2401 PC; Shimadzu) at $\lambda=650 \mathrm{~nm}$.

The monosaccharides from the hydrolysates were converted into their corresponding alditol acetates (26) and identified by gas-liquid chromatography (Hewlett-Packard 5890 A chromatograph; Hewlett-Packard, St. Louis, MO, USA) with a flame ionization detector and integrator 3393 A with an Ultra- 1 capillary column $(25 \mathrm{~m} \times 0.2 \mathrm{~mm})$ at temperatures from 175 to $270{ }^{\circ} \mathrm{C}$ and a rate of $10{ }^{\circ} \mathrm{C} / \mathrm{min}$ in a stream of nitrogen.
The content of nitrogen in protein was estimated as the difference between the total nitrogen determined by Kjeldahl method (27) and nitrogen in chitin. The content of nitrogen in chitin was estimated by dividing the chitin content by coefficient 6.89 (28). The total protein content was calculated by multiplying the protein nitrogen by 6.25 (27).

\section{Inhibitor preparation}

The precrushed and defatted rapeseed was treated with $96 \%$ ethanol at $30{ }^{\circ} \mathrm{C}$ for $30 \mathrm{~min}$. The ethanol extract that contained the phenolic compounds was separated by centrifugation at $5000 \mathrm{rpm}$ (centrifuge model OS-6MC; Dastan, Kazakhstan). From this extract the ethanol was removed by vacuum distillation. The resulting residue was dissolved in water to obtain the mass per volume ratio of the inhibitor in the solution from 0.17 to $4.77 \%$ (Table 2 ).

\section{Determination of chemical composition of the inhibitor}

The content of phenolic compounds was determined by Folin-Ciocalteu method (29). The composition of phenolic compounds was determined by thin layer chromatography (TLC) on CAMAG TLC Scanner 4 (Muttenz, Switzerland) apparatus equipped with automatic TLC

Table 2. Conditions used for preparation of the immobilized inhibitor

\begin{tabular}{|c|c|c|c|c|c|}
\hline \multirow{3}{*}{$\begin{array}{l}\text { Sample of immobilized } \\
\text { inhibitor }\end{array}$} & \multirow{3}{*}{$w$ (inhibitor)/\% } & \multicolumn{4}{|c|}{ Initial components } \\
\hline & & \multicolumn{2}{|c|}{ Matrix } & \multicolumn{2}{|c|}{ Inhibitor solution } \\
\hline & & Sample no. & $m / g$ & $w / \%$ & $V / \mathrm{mL}$ \\
\hline $1^{\prime}$ & 1 & 1 & 0.99 & 0.25 & 4 \\
\hline $1^{\prime}$ & 4 & 1 & 0.96 & 1.04 & 4 \\
\hline $1^{\prime}$ & 7 & 1 & 0.93 & 1.88 & 4 \\
\hline $1^{\prime}$ & 10 & 1 & 0.90 & 2.78 & 4 \\
\hline $1^{\prime}$ & 12 & 1 & 0.88 & 3.41 & 4 \\
\hline $1^{\prime}$ & 14 & 1 & 0.86 & 4.07 & 4 \\
\hline $1^{\prime}$ & 16 & 1 & 0.84 & 4.77 & 4 \\
\hline $2^{\prime}$ & 1 & 2 & 0.99 & 0.25 & 4 \\
\hline $2^{\prime}$ & 4 & 2 & 0.96 & 1.04 & 4 \\
\hline $2^{\prime}$ & 7 & 2 & 0.93 & 1.88 & 4 \\
\hline $2^{\prime}$ & 10 & 2 & 0.90 & 2.78 & 4 \\
\hline $2^{\prime}$ & 12 & 2 & 0.88 & 3.41 & 4 \\
\hline $2^{\prime}$ & 14 & 2 & 0.86 & 4.07 & 4 \\
\hline $2^{\prime}$ & 16 & 2 & 0.84 & 4.77 & 4 \\
\hline $3^{\prime}$ & 1 & 3 & 0.99 & 0.17 & 6 \\
\hline $3^{\prime}$ & 4 & 3 & 0.96 & 0.69 & 6 \\
\hline $3^{\prime}$ & 7 & 3 & 0.93 & 1.25 & 6 \\
\hline $3^{\prime}$ & 10 & 3 & 0.90 & 1.85 & 6 \\
\hline $3^{\prime}$ & 12 & 3 & 0.88 & 2.27 & 6 \\
\hline $3^{\prime}$ & 14 & 3 & 0.86 & 2.71 & 6 \\
\hline $3^{\prime}$ & 16 & 3 & 0.84 & 3.17 & 6 \\
\hline $4^{\prime}$ & 1 & 4 & 0.99 & 0.17 & 6 \\
\hline $4^{\prime}$ & 4 & 4 & 0.96 & 0.69 & 6 \\
\hline $4^{\prime}$ & 7 & 4 & 0.93 & 1.25 & 6 \\
\hline $4^{\prime}$ & 10 & 4 & 0.90 & 1.85 & 6 \\
\hline $4^{\prime}$ & 12 & 4 & 0.88 & 2.27 & 6 \\
\hline $4^{\prime}$ & 14 & 4 & 0.86 & 2.71 & 6 \\
\hline $4^{\prime}$ & 16 & 4 & 0.84 & 3.17 & 6 \\
\hline
\end{tabular}


sampler 4, twin trough chamber $(20 \mathrm{~cm} \times 10 \mathrm{~cm})$, chromatogram immersion device III, TLC plate heater III, automatic development chamber ADC2 and visualizer. The mobile phase was benzene/ethanol/acetic acid in a volume ratio of 90:16:9. The phenolic compounds were visualized by spraying the plates with water solution of ferrum chloride and ferrocyanide potassium (30). The sinapine and sinapic acid were identified by comparing the $R_{\mathrm{f}}$ value (distance eluent travels was $10 \mathrm{~cm}$ ) of the standard substances. The quantitative content of the sinapine and sinapic acid was perfomed by CAMAG TLC Scanner 4 apparatus. Additionally, the phenolic compounds were separated by TLC as described above, but the plate was not sprayed with water solution of ferrum chloride and ferrocyanide potassium. The spots of synapine and synapic acid were determined from the $R_{\mathrm{f}}$ value. These phenolic compounds were extracted with $96 \%$ ethanol at $30{ }^{\circ} \mathrm{C}$ for $30 \mathrm{~min}$ and their antilipase activity was determined (31).

\section{Determination of lipase and antilipase activity}

The lipase activity was determined according to the method of Jagdish et al. (32) with some modifications. The lipase (from porcine pancreas) was prepared at the concentration of $2.5 \mathrm{mg} / \mathrm{mL}$. The substrate was prepared by mixing $100 \mathrm{~mL}$ of olive oil and $150 \mathrm{~mL}$ of $2 \%$ polyvinyl alcohol.

The experimental sample was prepared as follows: 5 $\mathrm{mL}$ of the substrate and $4 \mathrm{~mL}$ of phosphate-citrate buffer $(\mathrm{pH}=7)$ were placed in the flask and kept at $37{ }^{\circ} \mathrm{C}$ for 15 $\mathrm{min}$. After that, $1 \mathrm{~mL}$ of the enzyme solution was added to the mixture and mixed thoroughly. The resulting mixture was kept at $37^{\circ} \mathrm{C}$ for $60 \mathrm{~min}$. Then, $30 \mathrm{~mL}$ of $90 \%$ ethanol were added to the mixture immediately to stop the reaction. Using phenolphthalein solution as the indicator, the solution was titrated with $0.05 \mathrm{M} \mathrm{NaOH}$ solution until a pink colour was obtained.

The control sample was prepared as follows: the mixture of the substrate and phosphate-citrate buffer $(\mathrm{pH}=7)$ was kept at $37{ }^{\circ} \mathrm{C}$. Then $30 \mathrm{~mL}$ of $90 \%$ ethanol and $1 \mathrm{~mL}$ of the enzyme solution were added and the mixture was titrated immediately.

The lipase activity (in U/g) was calculated according to the formula:

$$
\text { Lipase activity }=\left(V_{1}-V_{2}\right) \cdot V_{3} \cdot 50 / \gamma
$$

where $V_{1}$ is the volume of $0.05 \mathrm{M} \mathrm{NaOH}$ solution (in $\mathrm{mL}$ ) used for the experimental sample titration, $V_{2}$ is the volume of $0.05 \mathrm{M} \mathrm{NaOH}$ (in $\mathrm{mL}$ ) used for the control sample titration, $V_{3}$ is the titter of $0.05 \mathrm{M} \mathrm{NaOH}$ (in mL) and $\gamma$ is the concentration of the enzyme in the reaction mixture (in $\mathrm{g} / \mathrm{mL}$ ).

The lipase activity in the presence of the inhibitor was assayed as described above. A distinction was that the inhibitor containing $0.5-8.0 \mathrm{mg}$ of the phenolic compounds was added to the mixture at once after adding the enzyme solution (in experimental and control samples), and then the mixture was stirred thoroughly.

The antilipase activity of the inhibitor and Xenical was determined as the difference between the values of the lipase activity in the enzyme solution and the lipase activity in the enzyme solution in the presence of $20 \mathrm{mg}$ of Xenical.

\section{Determination of inhibitor properties}

For determination of the $\mathrm{pH}$ stability of the inhibitor, $6 \mathrm{mg}$ of the inhibitor were incubated in $100 \mathrm{~mL}$ of the medium with different $\mathrm{pH}$ values $(\mathrm{HCl}-\mathrm{KCl}, \mathrm{pH}=2$; citrate buffer, $\mathrm{pH}=5$; sodium phosphate buffer, $\mathrm{pH}=7$ and Tris$-\mathrm{HCl}, \mathrm{pH}=9)$ for $0-360 \mathrm{~min}$ at $(37 \pm 2)^{\circ} \mathrm{C}$. The samples were taken every $60 \mathrm{~min}$, the $\mathrm{pH}$ of the mixture was adjusted to $\mathrm{pH}=7$, and the antilipase activity of the samples was determined.

To determine the thermal stability of the inhibitor, 6 $\mathrm{mg}$ of the inhibitor were incubated at $(20 \pm 2),(37 \pm 2)$ and $(65 \pm 2){ }^{\circ} \mathrm{C}$ for $0-360 \mathrm{~min}$. The samples were taken every $60 \mathrm{~min}$, their temperature was adjusted to $(37 \pm 2)^{\circ} \mathrm{C}$, and the antilipase activity of the samples was determined. Remaining antilipase activity in that test, as well as those described below, were estimated as the percentage of the initial value of the antilipase activity of the inhibitor.

To predict the preservation of antilipase activity in the gastrointestinal tract, $6 \mathrm{mg}$ of inhibitor were placed in a flask and incubated in $100 \mathrm{~mL}$ of gastric juice at $(37 \pm 2)$ ${ }^{\circ} \mathrm{C}$ for $180 \mathrm{~min}$. After that, the $\mathrm{pH}$ in the flask was adjusted to $\mathrm{pH}=8$ and $100 \mathrm{~mL}$ of the natural bile were added. The mixture was incubated at $(37 \pm 2){ }^{\circ} \mathrm{C}$ for $180 \mathrm{~min}$. The inhibitor was kept in the gastric juice and bile, the samples were taken every $60 \mathrm{~min}$, the $\mathrm{pH}$ of the medium was adjusted to $\mathrm{pH}=7$ and the antilipase activity of the inhibitor was determined.

To determine the changes in antilipase activity during storage, $6 \mathrm{mg}$ of the inhibitor were incubated for 7 days at $(20 \pm 2){ }^{\circ} \mathrm{C}$ and relative humidity of $75 \%$. The antilipase activity was determined after $6 \mathrm{~h}$ and then after 1,3,5 and 7 days.

\section{Preparation of the immobilized lipase inhibitor}

To immobilize the phenolic compounds, the biopolymer matrix was impregnated with their solution. The content of the inhibitor in samples 1'-4' varied in the range from 1 to $16 \%$ (Table 2). For preparing samples 1' and 2', 4 $\mathrm{mL}$ of the inhibitor solution (with a mass per volume ratio of 0.25 to $4.77 \%$ ) were mixed with $1 \mathrm{~g}$ of matrices 1 and 2 . For preparing samples 3' and 4', $6 \mathrm{~mL}$ of the inhibitor solution (with a mass per volume ratio of 0.17 to $3.17 \%$ ) were mixed with $1 \mathrm{~g}$ of matrices 3 and 4 (Table 2). The immobilization temperature was varied from 20 to $40{ }^{\circ} \mathrm{C}$ during $50 \mathrm{~min}$ of immobilization, and the immobilization time was varied from 10 to $50 \mathrm{~min}$ at the temperature of $25^{\circ} \mathrm{C}$.

\section{Determination of antilipase activity of the immobilized inhibitor}

The antilipase activity of the immobilized inhibitor was determined as the difference between the lipase activity value of the enzyme solution (as described above) and the lipase activity value of the enzyme solution in the presence of $50 \mathrm{mg}$ of samples 1'-4' (all containing $12 \%$ of the inhibitor). The lipase activity of the enzyme solution in the presence of samples 1'-4' was determined in the same way as described for the original inhibitor. The antilipase activity of the immobilized inhibitor was calculated as a percentage of the activity of the original inhibitor. 


\section{Determination of immobilized inhibitor properties}

The thermal and $\mathrm{pH}$ stability of the immobilized inhibitor (samples 1'-4' with $12 \%$ of the inhibitor), as well as its remaining activity in the gastrointestinal tract were determined in the same way as the original inhibitor. To determine the $\mathrm{pH}$ stability and thermal stability, $50 \mathrm{mg}$ of samples 1'-4' were used. For determination of the changes in the antilipase activity during storage, $50 \mathrm{mg}$ of samples 1'-4' were kept for 12 months at $(20 \pm 2){ }^{\circ} \mathrm{C}$ and air humidity of $75 \%$. Every two months, their antilipase activity was determined. The remaining antilipase activity of the immobilized inhibitor in these tests was calculated as a percentage of the activity of the original inhibitor.

\section{Infrared spectroscopy and thermal analysis of the immobilized inhibitor}

Infrared (IR) spectroscopic study of the original inhibitor and samples 1'-4' with $12 \%$ of the inhibitor was carried out using the FTIR-8400S Fourier transform IR spectrophotometer (Shimadzu Corp.) in the range of 4000-400 $\mathrm{cm}^{-1}$. The IR spectra were compared according to Bikales and Segal (33). Differential thermal analysis of the mixture of the inhibitor and samples 1-4 and 1'-4' with $12 \%$ of inhibitor was carried out on the MOM derivatograph Q-1500 D (Paulik-Paulik-Erdey, Budapest, Hungary) (34). The samples were placed in an alumina cup and heated from 20 to $900{ }^{\circ} \mathrm{C}$ at a heating rate of $5{ }^{\circ} \mathrm{C} / \mathrm{min}$ in a nitrogen atmosphere. The flushing gas was passed through dry nitrogen at a rate of $100 \mathrm{~mL} / \mathrm{min}$.

\section{Statistical analysis}

The statistical analysis of the data was carried out by the dispersion and correlation analysis (35). The statistical differences were considered significant at $\mathrm{p}<0.05$. The results are expressed as mean values \pm standard deviation (S.D.).

\section{Results and Discussion}

\section{Inhibitor composition and its properties}

The rapeseed contained $7.2 \mathrm{mg} / \mathrm{g}$ of the phenolic compounds extracted with $96 \%$ ethanol. Six phenolic compounds in the extract were found by TLC method. Sinapine (5.9 $\mathrm{mg}$ per $\mathrm{g}$ of seed) and sinapic acid ( $0.7 \mathrm{mg}$ per $\mathrm{g}$ of seed) were dominant among them. The antilipase activity of the extract was $29800 \mathrm{U}$ per $\mathrm{g}$ of phenolic compounds, including the activity of sinapine, which was $18200 \mathrm{U}$ per $\mathrm{g}$ of phenolic compounds, and the activity of sinapic acid, which was $9700 \mathrm{U}$ per $\mathrm{g}$ of phenolic compounds. The antilipase activity of the phenolic compounds isolated from the rapeseed was comparable to that of the drug Xenical $(9800 \mathrm{U} / \mathrm{g})$. For this reason, it was expedient to obtain the dietary supplements with antilipase activity.

The lipase interacts with the lipids in the intestine (17), so the activity of the inhibitor must move along the digestive tract through the stomach $(\mathrm{pH} 2.0)$ and the intestine ( $\mathrm{pH}$ (9.0). Thus, the inhibitor stability under these conditions was an important factor.
As it is shown in Fig. 1 , at $\mathrm{pH}=2$ the antilipase activity decreased after incubation for $60 \mathrm{~min}$, then after $180 \mathrm{~min}$ it decreased 1.6 times and finally after 360 min only 40.2 $\%$ of the initial inhibitor antilipase activity remained. At $\mathrm{pH}=5$ the stability of the phenolic compounds was slightly
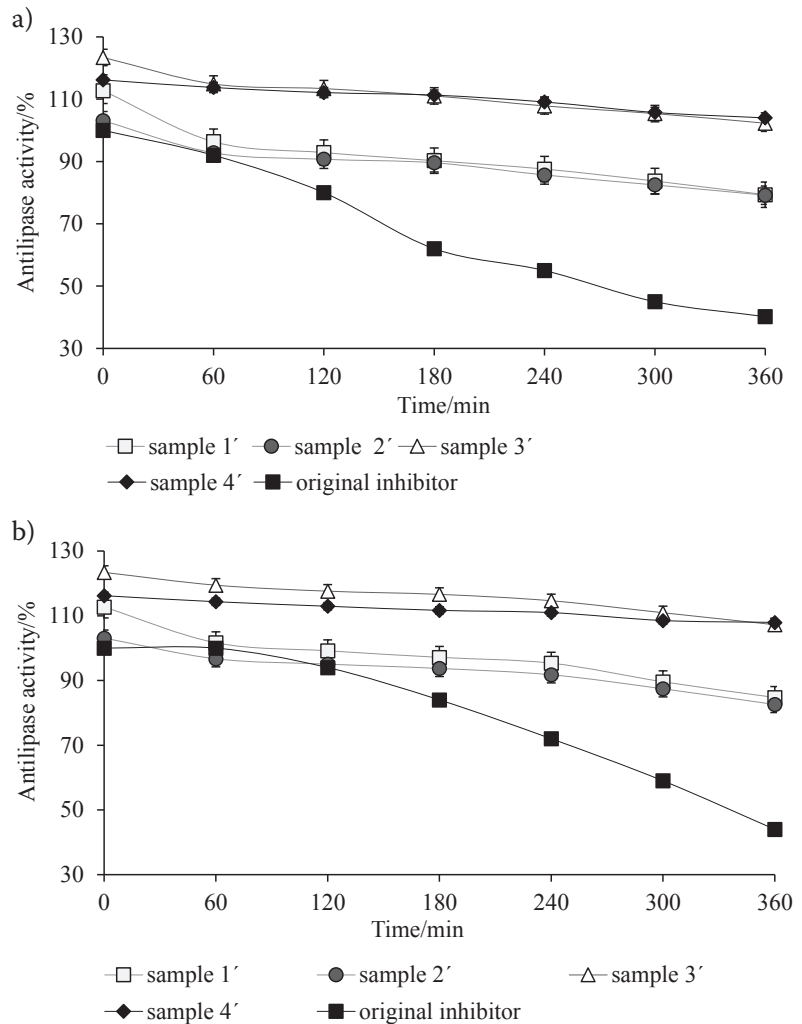

c)

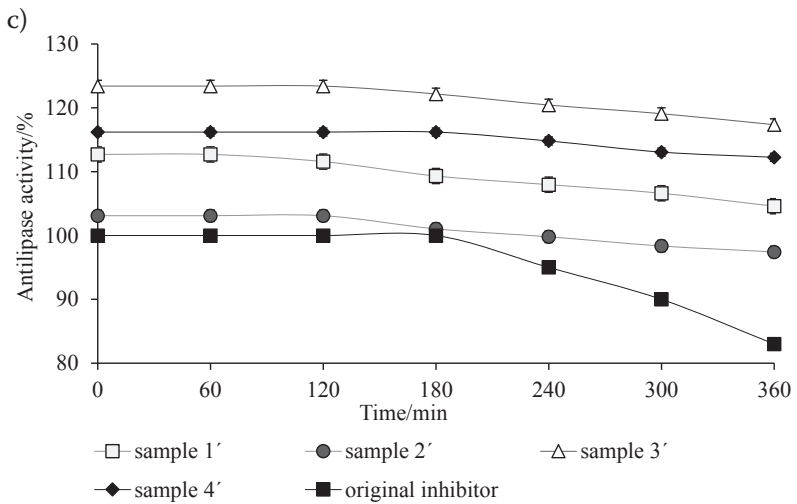

d)

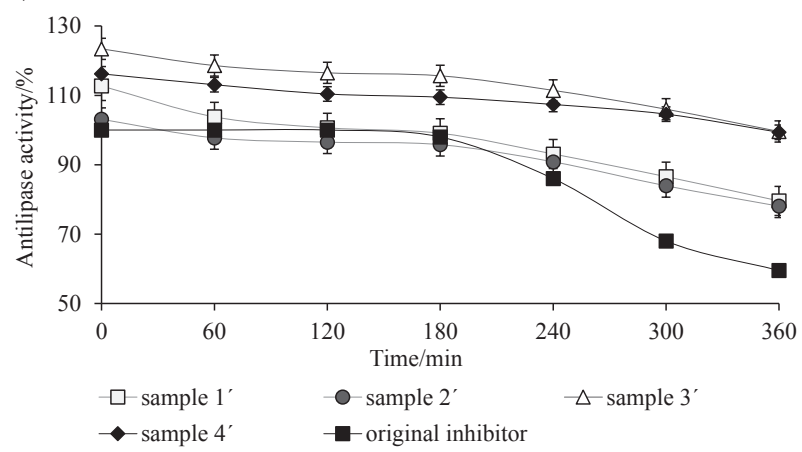

Fig. 1. The stability of samples 1'-4' at $\mathrm{pH}$ values of: a) 2.0, b) 5.0, c) 7.0 and d) 9.0 
higher. They were stable at $\mathrm{pH}=7$ and 9 for $180 \mathrm{~min}$. However, when the incubation time increased, the antilipase activity significantly decreased. Thus, it was necessary to use aqueous solution of phenolic compounds $(\mathrm{pH}=7)$ for the immobilization on the matrix.

Preservation of the antilipase activity of phenolic compounds during the contact with the gastric juice and bile was also studied. As can be seen from the data in Fig. 2 , the antilipase activity of phenolic compounds decreased mainly during the contact with the gastric juice. The bile had less effect on the antilipase activity. The residual activity of the inhibitor was low (40.4\% of the initial value). These results correlated with data for the $\mathrm{pH}$ stability of the phenolic compounds.

a)
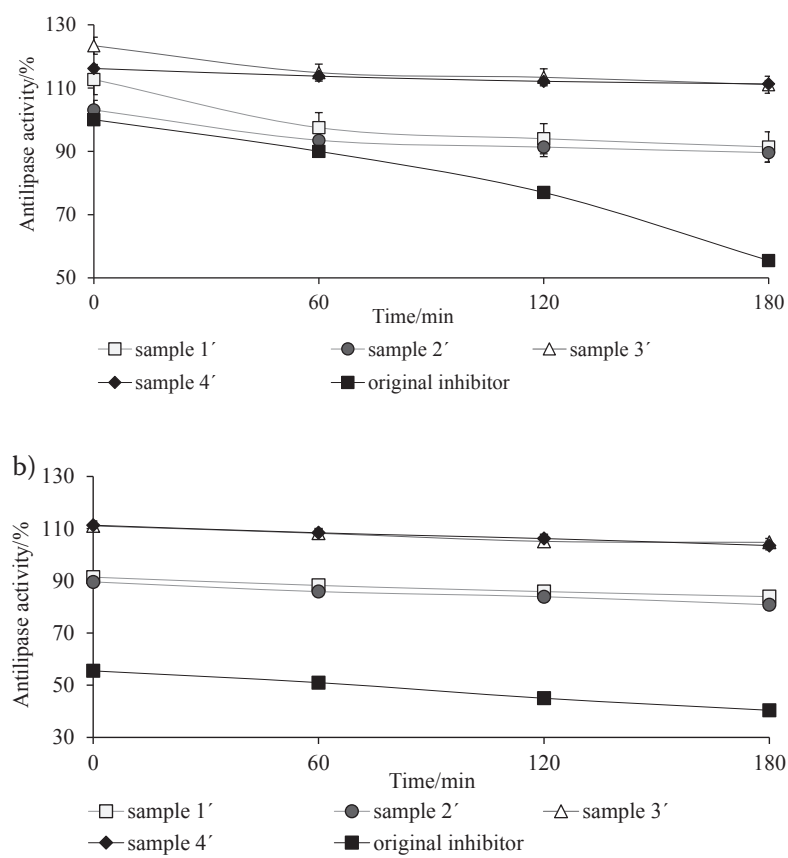

Fig. 2. Changes in the antilipase activity of samples 1'-4' under the conditions simulating normal digestion in: a) gastric juice and b) bile

We also studied the temperature effect on the antilipase activity of the inhibitor. It was important to predict the inhibitor stability in the human body when choosing the temperature conditions during preparation, drying and storing the samples of the immobilized inhibitor.

It was shown that the lipase inhibitor was stable at $(20 \pm 2){ }^{\circ} \mathrm{C}$ for $120 \mathrm{~min}$ of incubation (Fig. 3). However, when the phenolic compounds were kept at the same temperature for a long time, their activity was significantly reduced. If the phenolic compounds extracted from the rapeseed were kept at $(20 \pm 2){ }^{\circ} \mathrm{C}$ for $6 \mathrm{~h}$, their antilipase activity was reduced by $26.0 \%$ of the initial value. When incubation temperature increased, the antilipase activity of phenolic compounds decreased after $60 \mathrm{~min}$. Thus, it was necessary to investigate the influence of temperature in the range from 20 to $40{ }^{\circ} \mathrm{C}$ on the immobilization of phenolic compounds on the matrix, and on drying of the immobilized inhibitor at $(65 \pm 2){ }^{\circ} \mathrm{C}$. a)

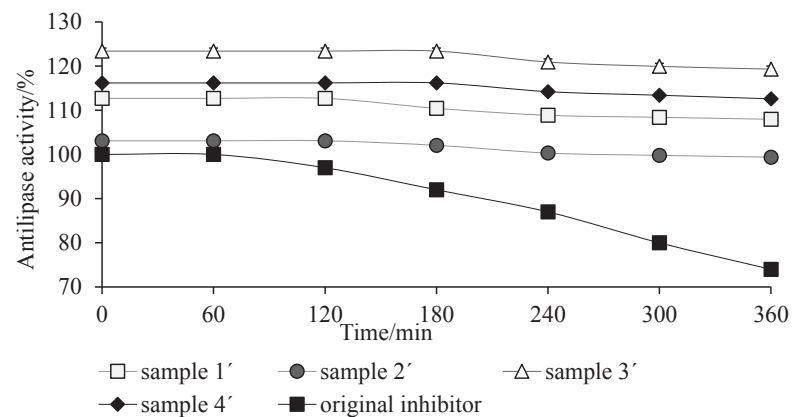

b)

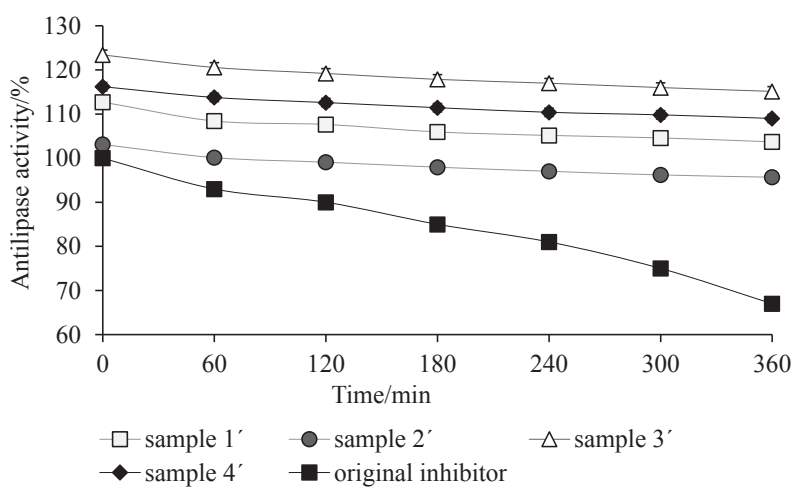

c)

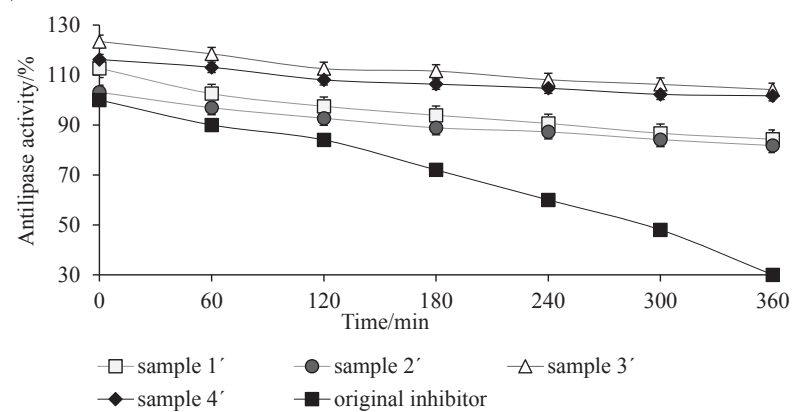

Fig. 3. Stability of samples 1'-4' at temperatures of: a) $(20 \pm 2)$, b) $(37 \pm 2)$ and c) $(65 \pm 2)^{\circ} \mathrm{C}$

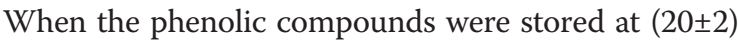
${ }^{\circ} \mathrm{C}$ and relative humidity of $75 \%$, their antilipase activity decreased by $32.1 \%$ after 1 day, by $51.4 \%$ after 3 days, by 69.1 $\%$ after 5 days and by $85.0 \%$ of the initial value after 7 days.

Thus, phenolic compounds extracted from the rapeseed inhibited the activity of pancreatic lipase. However, their effect was significantly reduced in the acid medium at $\mathrm{pH}=2$. In addition, the antilipase activity of the inhibitor significantly decreased at higher temperature, as well as during the long-term storage at $(20 \pm 2){ }^{\circ} \mathrm{C}$. This indicates out the necessity to stabilize the phenolic compounds.

\section{Immobilization of lipase inhibitor on the matrices}

Stabilization of the inhibitor was carried out by its immobilization on a matrix of Agaricus bisporus cell walls. Their chemical composition was shown in Table 3. They present a complex of biopolymers: polysaccharides, melanin and proteins. Samples 1-4 were obtained under different conditions and therefore the ratio of their components differed. In the polysaccharide hydrolyzate, only glucose 
Table 3. The chemical composition of samples of matrices

\begin{tabular}{|c|c|c|c|c|c|c|}
\hline \multirow[b]{2}{*}{ Sample } & \multicolumn{2}{|c|}{ Conditions } & \multicolumn{4}{|c|}{$w / \%$} \\
\hline & $\begin{array}{c}(m(\mathrm{NaOH}) / \\
V(\text { solution })) / \%\end{array}$ & $\begin{array}{l}\text { Time (expo- } \\
\text { sure)/min }\end{array}$ & Glucan & Chitin & Protein & Melanin \\
\hline 1 & \multirow{2}{*}{3} & 60 & $56.5 \pm 1.2$ & $14.0 \pm 0.3$ & $11.5 \pm 0.2$ & $13.8 \pm 0.3$ \\
\hline 2 & & 300 & $59.8 \pm 1.3$ & $15.8 \pm 0.3$ & $9.2 \pm 0.2$ & $11.9 \pm 0.2$ \\
\hline 3 & \multirow{2}{*}{7} & 60 & $47.9 \pm 1.0$ & $18.8 \pm 0.4$ & $11.1 \pm 0.2$ & $18.8 \pm 0.4$ \\
\hline 4 & & 300 & $38.8 \pm 0.8$ & $41.7 \pm 0.8$ & $3.0 \pm 0.1$ & $13.6 \pm 0.3$ \\
\hline
\end{tabular}

Data are expressed as mean value \pm S.D. of triplicate measurements

and glucosamine were detected by by gas liquid chromatography. Therefore, we concluded that polysaccharides were represented by glucan and chitin, which dominated in the samples (66.7-80.5\%). Chitin, compared to the other matrix components, is insoluble in the alkaline solutions. Therefore, the increase of the mass per volume ratio of the alkaline solution and extraction time increased the extraction of glucan and proteins. As a result, chitin content in the samples increased. This was especially clear in sample 4, which was obtained by using the alkaline solution with a maximum mass per volume ratio $(7.0 \%)$ and extraction time (300 $\mathrm{min})$.

\section{Effect of inhibitor content and chemical composition of the matrix on antilipase activity of immobilized inhibitor}

The original inhibitor was stable at $20-25^{\circ} \mathrm{C}$ for 60 min (Fig. 3). That is why its immobilization was carried out under these conditions.

The samples of the immobilized inhibitor 1'-4' were obtained as a result of the inhibitor interaction with matrices $1-4$. The influence of the inhibitor content in the matrix on the antilipase activity of the immobilized inhibitor is shown in Table 4. When the content of the inhibitor in the sample increased, the antilipase activity of the immobilized inhibitor also increased. When the inhibitor content was 12 $\%$, the antilipase activity of the immobilized inhibitor exceeded the activity of the original inhibitor in all samples. In samples 3' and 4' this effect was observed even if the content of the inhibitor in the sample was lower. A further increase in the inhibitor content to $16 \%$ did not lead to a significant change in the antilipase activity of the samples. Based on the obtained data, it was concluded that samples 1'-4' with $12 \%$ inhibitor should be used in the following experiments.

To objectively understand these results, additional studies were carried out. It was shown that matrices 1-4 had antilipase activity. In their presence, the hydrolysability of olive oil by lipase was reduced by $7.2-8.1 \%$. Sample 3 had the maximum antilipase activity. After the removal of melanin from matrix 3 , matrix 5 was obtained and the immobilization of the inhibitor in the mass per volume ratio of $7 \%$ was carried out on it. The antilipase activity of this sample was 1.3 times lower than that of sample 3', and it made up $80.5 \%$ of antilipase activity of the original inhibitor.

The high antilipase activity of the immobilized inhibitors 1'-4' was probably due to the synergistic effect, which was a result of the simultaneous presence of rapeseed phenolic compounds and Agaricus bisporus melanin. Melanin is classified as the condensed phenolic compound, which was confirmed by the fact that sample 3, with the highest content of melanin, had the maximum antilipase activity.

\section{Effect of immobilization conditions on antilipase activity of the immobilized inhibitor}

The analysis shows that the temperature of $20-25{ }^{\circ} \mathrm{C}$ was the most favourable for immobilization, preserving the antilipase activity of the obtained samples (Fig. 4a). When the immobilization temperature increased, the antilipase activity of the immobilized inhibitor consistently decreased. This fact was observed in all used matrices. It was concluded that the increase of the immobilization temperature most probably contributes to the destruction of labile phenolic compounds $(15,17)$.

Table 4. The antilipase activity of the immobilized inhibitor

\begin{tabular}{|c|c|c|c|c|}
\hline \multirow{2}{*}{$w$ (inhibitor) $/ \%$} & \multicolumn{4}{|c|}{ Antilipase activity/\% } \\
\hline & $1^{\prime}$ & $2^{\prime}$ & $3^{\prime}$ & $4^{\prime}$ \\
\hline 1 & $90.1 \pm 1.8$ & $88.1 \pm 1.7$ & $94.3 \pm 1.9$ & $91.3 \pm 1.8$ \\
\hline 4 & $90.4 \pm 1.9$ & $88.3 \pm 1.7$ & $95.3 \pm 1.9$ & $91.6 \pm 1.8$ \\
\hline 7 & $90.8 \pm 1.7$ & $88.9 \pm 1.8$ & $104.7 \pm 2.0$ & $91.9 \pm 1.8$ \\
\hline 10 & $100.4 \pm 2.0$ & $95.8 \pm 1.9$ & $116.9 \pm 2.2$ & $104.3 \pm 2.0$ \\
\hline 12 & $112.7 \pm 2.2$ & $103.1 \pm 2.0$ & $123.4 \pm 2.3$ & $116.2 \pm 2.2$ \\
\hline 14 & $112.4 \pm 2.3$ & $102.8 \pm 2.1$ & $123.0 \pm 2.3$ & $117.6 \pm 2.3$ \\
\hline 16 & $112.8 \pm 2.3$ & $101.6 \pm 2.0$ & $122.3 \pm 2.2$ & $117.0 \pm 2.2$ \\
\hline
\end{tabular}

Data are expressed as mean value \pm S.D. of triplicate measurements 
When the immobilization time was increased up to $30 \mathrm{~min}$, the antilipase activity of the immobilized inhibitor also increased (Fig. 4b). During this time the phenolic compound solution probably penetrated into the matrix, which improved the efficiency of immobilization. Increasing the duration of the process by more than $30 \mathrm{~min}$ did not give a positive result. Thus, it was expedient to carry out immobilization at the temperature of $20-25^{\circ} \mathrm{C}$ for $30 \mathrm{~min}$.

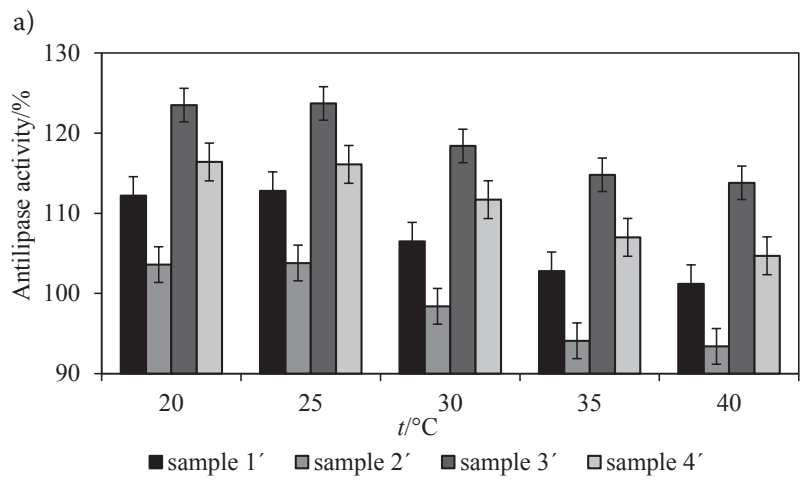

b)

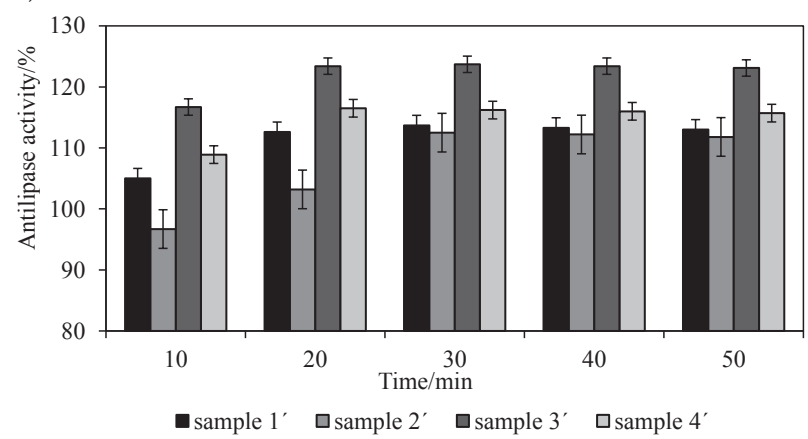

Fig. 4. The effect of immobilization conditions on the antilipase activity of samples 1'-4': a) temperature and b) time

\section{Binding of inhibitor immobilization in the matrix}

To confirm the inhibitor binding, the process of inhibitor immobilization was analyzed on sample 3 . After the contact of sample 3' (containing $12 \%$ of the inhibitor) with water at $(37 \pm 2)^{\circ} \mathrm{C}$ during $2 \mathrm{~h}$, only $4 \%$ of the initial phenolic compounds were found in the obtained solution. The phenolic compounds that passed into the solution showed no antilipase activity. Thus, it was concluded that the matrix completely adsorbed the phenolic compounds with antilipase activity.

When comparing the IR spectra of the original inhibitor and the immobilized inhibitor (samples 1'-4' with $12 \%$ of the inhibitor), it was found that the intense broad band with a maximum absorption at $3400 \mathrm{~cm}^{-1}$ was shifted to the low frequency region in comparison with the frequency of free $\mathrm{OH}$ groups. This indicated the presence of hydroxyl groups in hydrogen bonds. The intensity of the absorption bands at $1648-1690 \mathrm{~cm}^{-1}$ decreased. The absence of an absorption band of $3650 \mathrm{~cm}^{-1}$ led to the conclusion that practically all hydroxyl groups were part of the formed hydrogen bond.

The differential thermal analysis data are given in Table 5. At temperatures of 100 to $120^{\circ} \mathrm{C}$, the mass reduction of both the immobilized inhibitor (samples 1'-4' that con- tained $12 \%$ of the inhibitor) and the mixture of the inhibitor and samples 1-4 was detected because of the removal of free moisture, followed by the endothermic effect. When the temperature reached $360{ }^{\circ} \mathrm{C}$, the mass reduction of only the immobilized inhibitor was detected, followed by exothermic effect. This effect was not observed when the mixture of the inhibitor and samples 1-4 was used. An additional exothermic effect at $360^{\circ} \mathrm{C}$ of the immobilized inhibitor was probably caused by the destruction of the inhibitor-matrix bonds, which confirmed the immobilization of the inhibitor on the matrix. At higher temperature, the abrupt decrease in the mass of both the immobilized inhibitor and the mixture of the inhibitor and samples 1-4 was detected due to their destruction. Since the samples taken for the study contain the same amount of the inhibitor, there was no significant difference in their characteristics evaluated using this method. The results of thermal analysis and IR spectroscopy confirmed that immobilization of the lipase inhibitor on the matrix took place and that the inhibitor-matrix complex was formed by hydrogen bonds.

As it is known, the immobilization methods can be divided into chemical and physical methods. Physical methods are characterized by weaker interactions such as hydrogen bonds, hydrophobic interactions, Van der Waals forces, affinity binding, or mechanical containment of biologically active substance within the matrix. In the chemical method, formation of covalent bonds is achieved through ether, thioether, amide or carbamate bonds between the biologically active substance and matrix (36). There are four principal techniques for immobilization of the biologically active substance, namely adsorption, entrapment, covalent bonding and cross-linking (36). Thus, on the basis of the obtained data, it can be concluded that the adsorption took place during immobilization of the inhibitor on the matrix.

\section{Properties of the immobilized inhibitor}

The $\mathrm{pH}$ stability, thermal stability and the stability of the inhibitor immobilized on biopolymer matrix during storage were evaluated. Immobilized inhibitor samples 1'-4' with $12 \%$ of the inhibitor were used. It was found that after $360 \mathrm{~min}$ of incubation at $\mathrm{pH}=2$, the antilipase activity of the immobilized inhibitor was more than twice higher than the activity of the original inhibitor (Fig. 1), which was also the case after incubation in the medium with a higher $\mathrm{pH}$.

It was determined that samples 3' and 4' had maximum stabilizing effect in comparison with other samples of immobilized inhibitor. In the acid medium at $\mathrm{pH}=2$ and alkaline medium at $\mathrm{pH}=9$, their antilipase activity was 1.3 times higher than of samples 1' and 2'.

However, the $\mathrm{pH}$ stability data of the immobilized inhibitor were not sufficient to predict the preservation of its biological activity in the digestive tract. That is why the influence of the solutions that simulate liquid media of the gastrointestinal tract on the stability of immobilized inhibitor was studied.

The obtained results correspond to the data on the $\mathrm{pH}$ stability of the immobilized inhibitor samples (Fig. 2). The 
Table 5. Thermal effects of samples 1'-4'

\begin{tabular}{|c|c|c|c|}
\hline Sample & $t /{ }^{\circ} \mathrm{C}$ & $t_{\max } /{ }^{\circ} \mathrm{C}$ & Thermal effect \\
\hline \multirow{3}{*}{$1^{\prime}$} & $50-120$ & 105 & endo \\
\hline & $120-400$ & 360 & exo \\
\hline & $400-900$ & 535 & exo \\
\hline \multirow{3}{*}{$2^{\prime}$} & $50-120$ & 108 & endo \\
\hline & $120-400$ & 365 & exo \\
\hline & $400-900$ & 530 & exo \\
\hline \multirow{3}{*}{$3^{\prime}$} & $50-120$ & 110 & endo \\
\hline & $120-400$ & 369 & exo \\
\hline & $400-900$ & 540 & exo \\
\hline \multirow{3}{*}{$4 '$} & $50-120$ & 112 & endo \\
\hline & $120-400$ & 368 & exo \\
\hline & $400-900$ & 543 & exo \\
\hline \multirow{2}{*}{ 1+inhibitor } & $50-120$ & 102 & endo \\
\hline & $120-900$ & 520 & exo \\
\hline \multirow{2}{*}{$2+$ inhibitor } & $50-120$ & 105 & endo \\
\hline & $120-900$ & 523 & exo \\
\hline \multirow{2}{*}{ 3+inhibitor } & $50-120$ & 101 & endo \\
\hline & $120-900$ & 528 & exo \\
\hline \multirow{2}{*}{ 4+inhibitor } & $50-120$ & 107 & endo \\
\hline & $120-900$ & 526 & exo \\
\hline
\end{tabular}

antilipase activity of the immobilized inhibitor was 2.0-2.6 times higher than that of the original one. This fact made possible to predict preservation of high activity of the immobilized inhibitor in human digestive tract.

The significant increase in the stability of phenolic compounds as a result of immobilization was probably due to the fact that matrices $1-4$ contained chitin. This polysaccharide consists of N-acetyl-D-glucosamine units. During alkaline treatment of the samples at high temperature, deacetylation took place and amino groups are released (19). As a result of this process, the matrix shows antacid properties, which are the result of the substance ability to increase the $\mathrm{pH}$ value of acid medium. Matrices 3 and 4 were obtained by long-term alkaline treatment (300 min) and, as it was shown in a previous study (21), these matrices contained more amino groups than matrices 1 and 2 . As a result, matrices 3 and 4 had more pronounced antacid properties than matrices 1 and 2, and they better preserve the properties of phenolic compounds in acid medium.

Thermal stability of the inhibitor also increased as a result of its immobilization (Fig. 3). High antilipase activity of samples 1 ' -4 ' at $(37 \pm 2)^{\circ} \mathrm{C}$ for $6 \mathrm{~h}$ was observed. That is why at the temperature of the human body they show the antilipase activity. After incubation of the original inhibitor at $(65 \pm 2){ }^{\circ} \mathrm{C}$ for $360 \mathrm{~min}$, its residual antilipase activity was $30 \%$, which was $2.7-3.5$ times lower than the residual activity of the immobilized inhibitor. The samples $1^{\prime}-4$ ' were stable at $(65 \pm 2)^{\circ} \mathrm{C}$. That is why we recommend them for dry use by both freeze drying and spray drying. The thermal and the pH stability of samples 3' and 4' were higher than of samples 1' and 2'.
Another important characteristic of the immobilized inhibitor was the preservation of its antilipase activity during storage. After 6 months of storage, the antilipase activity of samples 1'-4' with $12 \%$ of the inhibitor was $88.5-112.8 \%$ of the activity of the original inhibitor, but the original inhibitor lost $85.0 \%$ of its activity after 7 days of storage (Fig. 5). After 6 months of storage, samples 2' and 4' had the highest antilipase activity. After 12 months of storage, the antilipase activity of samples 1'-4' remained at a high level, but of sample 4' was significantly higher than of other samples.

The stability of samples of the immobilized inhibitor with the increase of temperature to $(37 \pm 2)$ and $(65 \pm 2){ }^{\circ} \mathrm{C}$, as well as during long-term storage at $(20 \pm 2)^{\circ} \mathrm{C}$ was stipulated by the fact that the matrix prevented the transformation of rapeseed phenolic compounds. As it is known, the change in the phenolic compounds structure led to the loss of their properties. As a result, the phenolic compounds did not show any antilipase activity. Such transformation of their properties could be the result of the oxidation due to contact with oxygen from the air (17).

As it is shown in a previous study (21), matrices 1-4 had high antioxidant properties. Such properties can be explained by the presence of melanin in their composition and free amino groups in the chitin molecule. Therefore, they were able to inhibit the oxidation of rapeseed phenolic compounds in contact with oxygen from the air and preserve their antilipase activity.

Analyzing the obtained results, it should be noted that high $\mathrm{pH}$ stability, thermal stability and stability of the immobilized inhibitor during storage were related to the prop- 


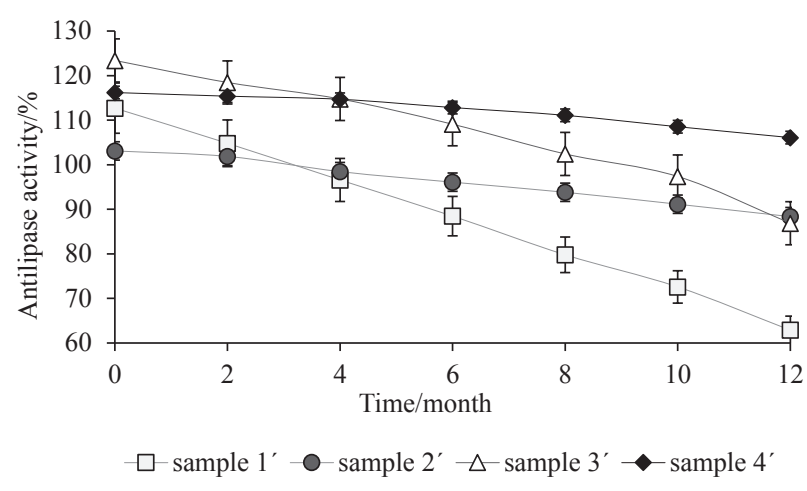

Fig. 5. Changes in the antilipase activity of samples 1'-4' during storage

erties of matrix biopolymers. Immobilization of biologically active substances usually led to the partial decrease in their activity $(19,20,36,37)$. For example, after the immobilization of protease on polysaccharides isolated from cereals, the activity of the immobilized enzyme was $55 \%$ of the activity of the original enzyme (37). Lipase immobilized on cereal polysaccharides showed $72.4 \%$ of the initial enzyme activity (37). After the protease inhibitor was immobilized on cereal polysaccharides, the obtained immobilized inhibitor had only $33 \%$ of the activity of the original inhibitor. That is why in this work the matrices with antilipase activity where chosen, and during immobilization the synergistic effect was observed, so as a result, the activity of phenolic compounds did not decrease and in samples 1'-4' it exceeded the activity of the original inhibitor.

As it is known, immobilization of the biologically active substances leads to the increase of their resistance to changes in environmental conditions $(19,20,35,36)$. For example, after incubation of protease, lipase and protease inhibitor in acid medium, they completely lose their activity. However, all immobilized samples had higher $\mathrm{pH}$ stability than the original biologically active substances. After their incubation in the acid medium, the activity of the immobilized biologically active substance was around 20-45\% of the activity of the original biologically active substances.

Due to the fact that the matrix also contributed to the preservation of the activity under different $\mathrm{pH}$ and temperature, in this work the matrices that could preserve the antilipase activity of the phenolic compounds were chosen. As a result of the immobilization of rapeseed phenolic compounds on the matrix, the $\mathrm{pH}$ stability, thermal stability, and stability during storage of the immobilized inhibitor were enhanced. Apart from that, the antilipase activity of the immobilized inhibitor after its incubation in the acid medium was notably higher than the activity of the above-mentioned biologically active substance, due to the fact that the used matrices had antacid and antioxidant properties. Thus, the immobilization of the inhibitor on biopolymers from Agaricus bisporus provided the stable form of the lipase inhibitor.

In most cases, during changes in the environmental conditions, the antilipase activity of samples 3' and 4' exceeded the activity of the original inhibitor. Only after storage for 12 months the activity of sample 3' insignificantly decreased. Taking into account the possibility of practical use of the obtained results for the development of production technology, it is economically viable to obtain sample 3', since the use of longer treatment at high temperature will lead to the increase of the obtained product cost.

\section{Conclusions}

The stabilized form of lipase inhibitor was obtained by its immobilization on the biopolymers from Agaricus bisporus cell walls. It had significantly better $\mathrm{pH}$ and thermal stability than the original inhibitor. It was stable under the conditions of the digestive tract. The immobilized inhibitor retained the activity for a long time during storage. The sample that had $12 \%$ of the inhibitor and the matrix containing $47.9 \%$ glucan, $18.8 \%$ chitin, $18.8 \%$ melanin and $11.1 \%$ proteins showed the best characteristics. The best immobilization was carried out at $20-25{ }^{\circ} \mathrm{C}$ for 30 min. The hydrogen bonds between the inhibitor and the matrix were formed during immobilization.

\section{References}

1. Ogden CL, Yanovski SZ, Carrol MD, Flegal KM. The epidemiology of obesity. Gastroenterology. 2007;132:1087-102. https://doi.org/10.1016/j.gtc.2009.12.014

2. Lavie CJ, Milani RV, Artham SM, Patel DA, Ventura HO. The obesity paradox, weight loss, and coronary disease. Am J Med. 2009;122:1106-14.

https://doi.org/10.1016/j.amjmed.2009.06.005

3. Uretsky S, Masserli FH, Bangalore S, Champion A, Cooper-Dehoff RM, Zhou Q, et al. Obesity paradox in patients with hypertension and coronary artery disease. Am J Med. 2007;120:86370 .

https://doi.org/10.1016/j.amjmed.2007.05.011

4. Rahmouni K, Correia ML, Haynes WG, Mark AL. Obesity-associated hypertension: New insights into mechanisms. Hypertension. 2005;45:9-14.

https://doi.org/0.1161/01.HYP.0000151325.83008.b4

5. James WPT, Caterson ID, Coutinho W, Finer N, Van Gaal LF, Maggioni AP, et al. Effect of sibutramine on cardiovascular outcomes in overweight and obese subjects. New Engl J Med. 2010;363:905-17.

https://doi.org/10.1056/NEJMoa1003114

6. Chanoine JP, Hampl S, Jensen C, Boldrin M, Hauptman J. Effect of orlistat on weight and body composition in obese adolescents: A randomized controlled trial. JAMA. 2005;293:2873-83. https://doi.org/10.1001/jama.293.23.2873

7. Maahs D, de Serna DG, Kolotkin RL, Ralston S, Sandate J,Qualls C, Shade DS. Randomized, double-blind, placebo-controlled trial of orlistat for weight loss in adolescents. Endocr Pract. 2006;12:18-28. https://doi.org/10.4158/EP12118

8. Grinevich VB, Sas EI, Kravchuk YA, Efimov OI. Abdominal obesity: clinical and social aspects of the problem. Farmateka. 2012;16:29-34 (in Russian).

9. Verpoorte R. Pharmacognosy in the new millennium: Leadfinding and biotechnology. J Pharm Pharmacol. 2000;52:253-62. https://doi.org/10.1211/0022357001773931

10. Slanc P, Doljak B, Kreft S, Lunder M, Janeš D, Strukelj B. Screening of selected food and medicinal plant extracts for pancreatic lipase inhibition. Phytother Res. 2009;23:874-7. https://doi.org/10.1002/ptr.2718

11. He R, Chen L, Lin B, Matsui Y, Yao X, Kurihara H. Beneficial effects of oolong tea consumption on diet-induced overweight and obese subjects. Chin J Int Med. 2009;15:34-41. https://doi.org/10.1007/s11655-009-0034-8 
12. Birari R, Roy SK, Singh A, Bhutani KK. Pancreatic lipase inhibitory alkaloids of Murrayakoenigii leaves. Nat Prod Commun. 2009;4:1089-92.

13. Seigler DS, Pauli GF, Frohlich R, Wegelius E, Nahrstedt A, Glander KE, Ebinger JE. Cyanogenic glycosides and menisdaurin from Guazuma ulmifolia, Ostrya virginiana, Tiquilia plicata, and Tiquilia canescens. Phytochemistry. 2005;66:1567-80. https://doi.org/10.1016/j.phytochem.2005.02.021

14. Francisco IA, Pinotti MHP. Cyanogenic glycosides in plants. Braz Arch Biol Technol. 2000;43:487-92. https:// doi.org/10.1590/S1516-89132000000500007

15. Naczk M, Amarowicz R, Sullivan A, Shahidi F. Current developments on polyphenolics of rapeseed/canola: a review. Food Chem. 1998;62:489-502. https://doi.org/10.1016/S0308-8146(97)00198-2U

16. Naczk M, Pink J, Amarowicz R, Pink D, Shahidi F. Multivariate model for the prediction of soluble condensed tannins in crude extracts of polyphenols from canola and rapeseed hulls. J Am Oil Chem Soc. 2001;78:411-4. https://doi.org/10.1007/s11746-001-0276-1

17. Macheix JJ, Fleuriet A, Billot J. Fruit phenolics. Boca Raton, FL, USA: CRC Press; 1990.

18. Cherno NK, Krusir GV, Yashkina VV. Prospects for the use of certain types of vegetable raw materials as lipase inhibitors. Cereals and fodder. 2004;3:15-7 (in Russian).

19. Krajewska B. Chitin and its derivative as supports for immobilization of enzymes. Acta Biotechnol. 1991;1:269-77. https://doi.org/10.1002/abio.370110319

20. Liese A, Hilterhaus L. Evaluation of immobilized enzymes for industrial applications. Chem Soc Rev. 2013;42:6236-49. https://doi.org/10.1039/c3cs35511j

21. Cherno NK, Nikitina OV. Biologically active supplement based on biopolymers of button mushroom (Agaricus bisporus). News of institutes of higher education: Food Technol. 2014;4:66-9 (in Russian).

22. Cherno N, Osolina S, Nikitina A. Chemical composition of Agaricus bisporus and Pleurotus ostreatus fruting bodies and their morphological parts. Food Environ Safe. 2013;4:291-9.

23. Selvakumar P, Rajasekar S, Periasamy K, Raaman N. Isolation and characterization of melanin pigment from Pleurotus cystidiosus (telomorph of Antromycopsis macrocarpa). World J Microbiol Biotechnol. 2008;24:2125-31. https://doi.org/10.1007/s11274-008-9718-2
24. Chung CW, Nickerson WJ. Polysaccharide synthesis in growing yeast. J Biol Chem. 1954;208:395-407.

25. Lane Smith R, Gilkerson E. Quantitation of glycosaminoglycan hexosamine using 3-methyl-2-benzothiazolone hydrazone hydrochloride. Anal Biochem. 1979;98:478-80. https://doi.org/10.1016/0003-2697(79)90170-2

26. Laine RA, Esselman WJ, Sweely CC. Gas-liquid chromatography of carbohydrates. Method Enzymol. 1972;18:159-67. https://doi.org/10.1016/0076-6879(72)28012-0

27. Manzi P, Gambelli L, Marconi S, Vivanti V, Pizzoferrato L. Nutrients in edible mushrooms: An inter-species comparative study. Food Chem. 1999;65:477-82. https://doi.org/10.1016/S0308-8146(98)00212-X

28. Ofenbeher-Miletić I, Stanimirović D, Stanimirović S. On determination of chitin content in mushrooms. Plant Food Hum Nutr. 1984;34:197-201. https://doi.org/10.1007BF01091469

29. Ragazzi E, Veronese G. Quantitative analysis of phenolics compounds after thin-layer chromatographic separation. J Chromatogr A. 1973;34:369-75. https://doi.org/10.1016/S0021-9673(00)92204-0

30. Amarowicz R, Karamać M, Rudnicka B, Ciska E. TLC separation of glucopyranosyl sinapate and other phenolic compounds from rapessed. Fett Wissenschaft Technol. 1995;97:330-3. https://doi.org/10.1002/lipi.19950970905

31. Spangenberg B, Poole CF, Weins C. Quantitative thin-layer chromatography. Berlin, Germany: Springer-Verlag; 2011.

32. Jagdish P, Deepa V, Rohan G, Bhagat RD. Production of microbial lipases isolated from curd using waste oil as a substrate. Res J Pharm Biol Chem Sci. 2013;4:831-9.

33. Bikales NM, Segal L. Cellulose and cellulose derivatives. New York, USA: Wiley-Interscience; 1971.

34. Paulik F, Paulik J, Erdey L. Derivatography: A complex method in thermal analysis. Talanta. 1966;13:1405-30. https://doi.org/10.1016/0039-9140(66)80083-8

35. Albright SC, Winston WL, Zappe CJ. Data analysis and decision making. Mason, OH, USA: South-Western Cengage Learning; 2010.

36. Guisán JM. Immobilization of enzymes and cells. In: Methods in biotechnology, Walker JM, editor. Totowa, NJ, USA: Humana Press Inc; 2006. https://doi.org/10.1007/978-1-59745-053-9

37. Cherno NK, Krusir GV, Kovalenko OV. The biocorrectors of digestion processes. Odessa, Ukraine: TEES; 2009 (in Ukrainian). 